\title{
Characteristics of Precipitation Particles Measured by PARSIVEL Disdrometer at a Mountain and a Coastal Site in Korea
}

\author{
Joo Wan Cha ${ }^{1}$. Seong Soo Yum ${ }^{2}$ \\ Received: 17 October 2019 /Revised: 26 February 2020 / Accepted: 7 March 2020 / Published online: 14 April 2020 \\ (C) The Author(s) 2020
}

\begin{abstract}
This study analyzed HC (Hydrometeor Classification), rain rate, and DSD (Drop Size Distribution) observed using an optical disdrometer, parsivel, at a mountain (Daegwallyeong, DG) and a coastal site (Mokpo, MP) over 2 years (2010-2011). The HC accuracies of the drizzle, rain, and snow were about $95 \%, 87 \%$, and $80 \%$ respectively. The $\mathrm{R}^{2}$ (coefficient of determination) of the parsivel with TB (Tipping Bucket) rain gauge was 0.91 at MP and 0.96 at DG. The shapes of drizzle and rain DSD observed at DG and MP were similar while the variation in snow DSD was easily influenced by weather condition such as temperature and wind speed. The relatively warm temperature $\left(-5{ }^{\circ} \mathrm{C} \sim-0{ }^{\circ} \mathrm{C}\right)$ increased the snow particle number concentration at around $0.6 \sim 1 \mathrm{~mm}$ diameter and the relatively cold temperature $\left(-15^{\circ} \mathrm{C} \sim-10^{\circ} \mathrm{C}\right)$ decreased it above $2 \mathrm{~mm}$ diameter. Although wind speed was not a strong factor in snow DSD, larger particles were apt to form in relatively strong wind conditions. Due to different wind directions for the maritime and continental regions, snow particle number density (N(D)) at MP and DG exhibited large differences in terms of snow DSD shape and the number concentration. For instance, in the maritime precipitation, snow DSD shape at MP was broader than that at DG and small-size snow particles were observed at DG more frequently than at MP. In addition, camera-observed snow particle type measurement was carried out at DG in January to March 2010. During the measurement at DG, a mixed type of plate and column was the most frequent and an aggregation of plate type frequently occurred at lower temperatures.
\end{abstract}

Keywords Hydrometeor classification · Drop size distribution $\cdot$ Optical disdrometer

\section{Introduction}

Hydrometeor classification (HC) and Drop Size Distribution (DSD) of precipitation particles are essential information for precipitation physics research (Mason et al. 2017). For that reason, several HC, DSD, and falling velocity measurement using optical devices have been conducted in recent years (e.g, Löffler-Mang and Joss 2000; Caracciolo et al. 2006; Battaglia et al. 2010). Moreover, HC, DSD, and rainfall intensity

Responsible Editor: Lei Bi.

Joo Wan Cha

jwcha@korea.kr

1 National Institute of Meteorological Sciences/KMA, Seogipo, Jeju, South Korea

2 Department of Atmospheric Sciences, Yonsei University, Seoul, South Korea become important factors in satellite communication and electronic wave research because they are major sources of error in predicting the attenuation of the electronic wave data (Timothy and Ong 2002).

As part of a leading group in this research field, LöfflerMang and Joss (2000) used aircraft to observe ice (or snowflake) particle DSD. Some other researches also showed that optical instruments could measure physical characteristics such as DSD and falling velocity. Uijlenhoet et al. (2003a) investigated DSD variability within a squall line consisting of convective, transition, and stratiform rain regimes. However, only a few precipitation HC and DSD observations in the surface have been carried out in Korea (You et al. 2004; Cha et al. 2010). Optical observation of HC and DSD has rarely been conducted in Korea. There were implemented about the comparison of snow particle images with their DSD using parsivel disdrometer (OTT MESSTECHNIK GmbH and Co 2005) in Korea for the first times. 
Fig. 1 Observation sites and the simple classification of precipitation type (At DG, C-type is a continental-like precipitation (west wind direction) and M-type is a maritime-like precipitation (East wind direction). At MP, Ctype is a continental-like precipitation (East wind direction) and M-type is a maritime-like precipitation (West wind direction))

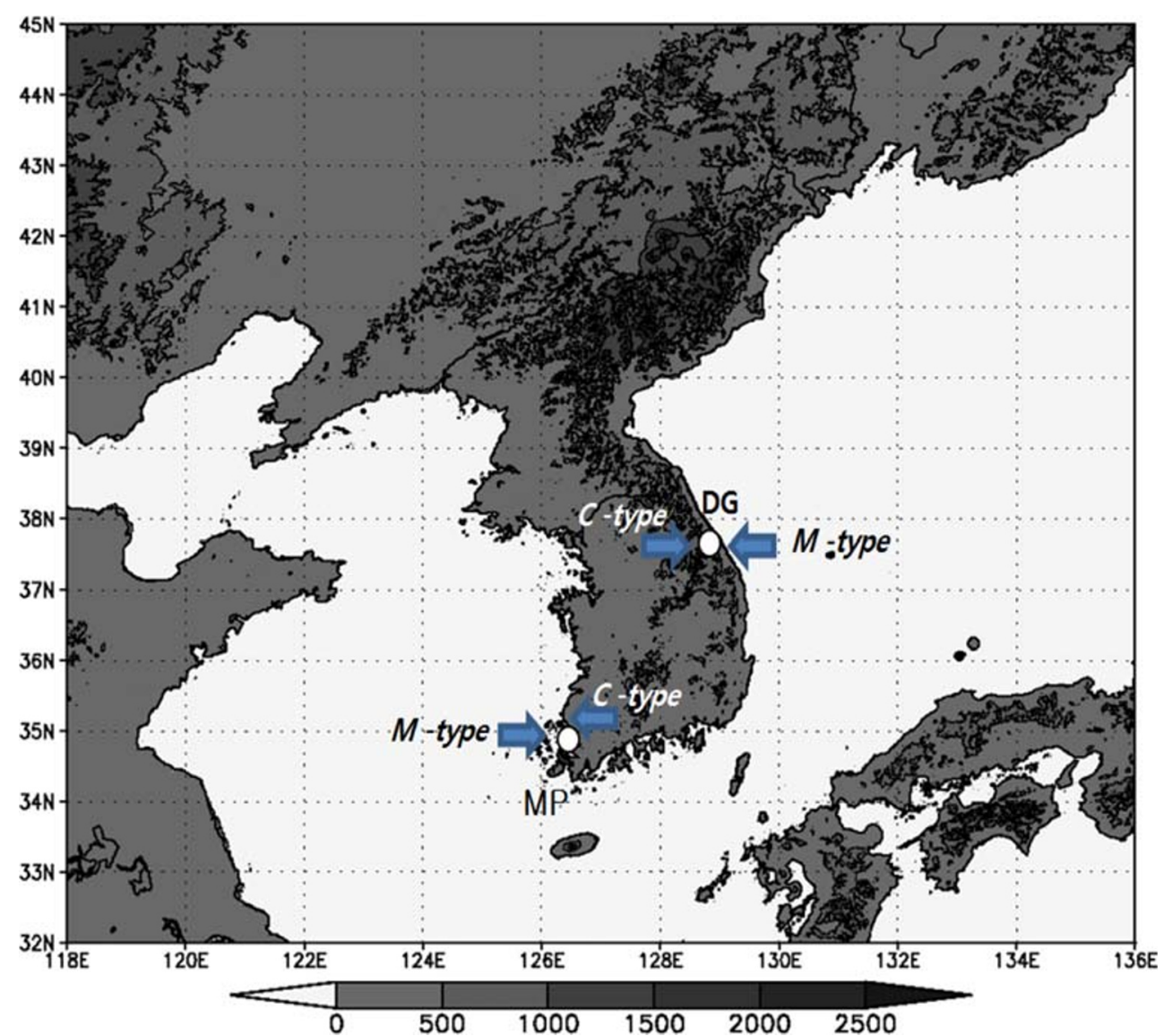

In this study, we present the results of long term intensive precipitation particle measurements using PARSIVEL disdrometer (hereafter referred as "disdrometer") at a mountain and a coastal site. Importantly this study takes into account the weather conditions because they strongly affect the characteristics of DSD and are necessary to understand the physical effects on the DSD shape.

\section{Data and Instrument}

\subsection{Measurement Sites and Instrument}

The locations of the two measurement sites are: Daegwallyeong (hereafter, DG) $\left(37^{\circ} 41^{\prime} \mathrm{N}, 128^{\circ} 45^{\prime} \mathrm{E}\right.$, altitude $\left.845 \mathrm{~m} \mathrm{ASL}\right)$ in
Kangwon province and Mokpo weather station (hereafter, MP) $\left(34^{\circ} 49^{\prime} \mathrm{N}, 126^{\circ} 23^{\prime} \mathrm{E}, 37.9 \mathrm{~m} \mathrm{ASL}\right)$ in Chunnam province of Korea (Fig. 1). Cha et al. (2009) showed that stratiform precipitation frequently occurred at DG due to its mountainous topographical characteristics and east winds frequently brought orographic precipitation, while in MP convective precipitation was frequently observed due to its susceptibility to maritime climate (typhoons and heavy rains) on the southern coast of the Korean peninsula. Table 1 shows the general characteristics of the weather conditions at the two sites for 2010-2011. For example, the maximum $1 \mathrm{~h}$ rainfall amount at MP was larger than that at DG but the annual accumulated rainfall amount at DG was larger than that at MP, meaning that precipitation tended to be more intense at MP than at DG but the total precipitation was larger at DG. In addition, the CAPE (Convective Available
Table 1 Weather condition for observational sites from 2010 to 2011(T: Average hourly mean temperature, R: annual accumulated rainfall amount, Max. R: maximum $1 \mathrm{~h}$ rainfall amount, $\mathrm{S}$ : annual accumulated snowfall amount, WS: average wind speed, RH: average relative humidity, and CA: Average cloud amount)

\begin{tabular}{llllllll}
\hline $\begin{array}{l}\text { Avg. } \\
\text { Site }\end{array}$ & $\mathrm{T}\left({ }^{\circ} \mathrm{C}\right)$ & $\mathrm{R}(\mathrm{mm})$ & $\mathrm{M} \mathrm{ax} . \mathrm{R}(\mathrm{mm})$ & $\mathrm{S}(\mathrm{cm})$ & $\mathrm{WS}\left(\mathrm{m} \mathrm{s}^{-1}\right)$ & $\mathrm{RH}(\%)$ & $\mathrm{CA}(1 / 10)$ \\
\hline DG & 7 & 1489 & 31 & 51 & 9 & 72 & 5.6 \\
MP & 13 & 1158 & 45 & 14 & 3 & 78 & 5.5 \\
\hline
\end{tabular}


Fig. 2 Comparison of the parsivel rain rate with the tipping bucket (TB) rain gauge rain rate from hourly data at (a) DG and (b) MP in $2010 \sim 2011$ after data QC
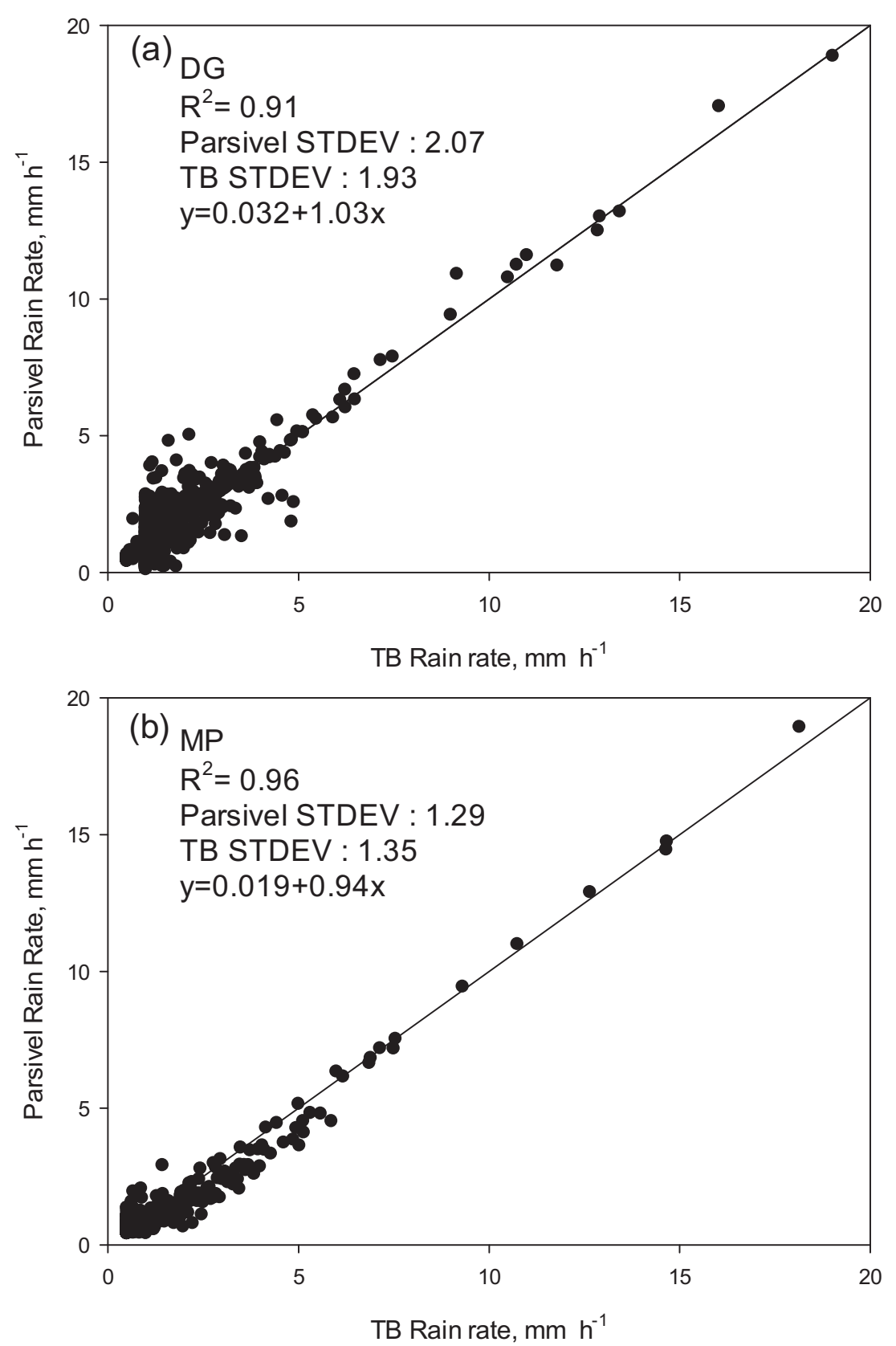

Potential Energy), which represents the amount of buoyant energy available for accelerating air parcel vertically or the amount of work to be done to ascend a parcel of air through the environment was larger at DG than that at MP (Cha et al. 2009).

The instrument deployed for this study is the parsivel disdrometer (OTT MESSTECHNIK GmbH and Co 2005), a laser-based optical instrument for precipitation measurement of all types. The laser sensor of the parsivel disdrometer produces a horizontal strip of light. The emitter and receiver are integrated into a single protective housing. To determine the particle speed, the duration of the signal is measured. A signal begins as soon as a precipitation particle enters the light strip and ends when it has completely left the light strip.
Table 2 Comparison of the accuracy of parsivel observation with human eye-observation for hydrometors at DG in 2010

\begin{tabular}{cll}
\hline Hydrometeor & Accuracy & No. of Cases \\
\hline Rain & $95 \%$ & True: 97 \\
& & False: 5 \\
Drizzle & $87 \%$ & Total: 102 \\
& & True: 23 \\
Snow & \multirow{2}{*}{ False: 3} \\
& & Total: 26 \\
& & True: 55 \\
Total & $87 \%$ & False: 11 \\
& & Total: 66 \\
& & True: 175 \\
& & False: 19 \\
& & Total: 194 \\
\hline
\end{tabular}




\subsection{Data}

The $\mathrm{HC}$, rain rate, and DSD were obtained from the disdrometer measurement at DG and MP for two years (2010-2011). A tipping bucket (TB) rain gauge was also installed to measure the rain rate at the two sites for the same period. To verify the disdrometer data of rain rate and $\mathrm{HC}$, this study compared the rain rate data of the disdrometer with that of the TB rain gauge and the disdrometer with $\mathrm{HC}$ data the human-observed weather event records. The utilized channel ranges of the disdrometer was $3 \mathrm{rd}(0.32 \mathrm{~mm})$ to $21 \mathrm{st}$ ( $5.5 \mathrm{~mm})$ for rain and $3 \mathrm{rd}(0.32 \mathrm{~mm})$ to 26 th $(11 \mathrm{~mm})$ for snow. To

(a)

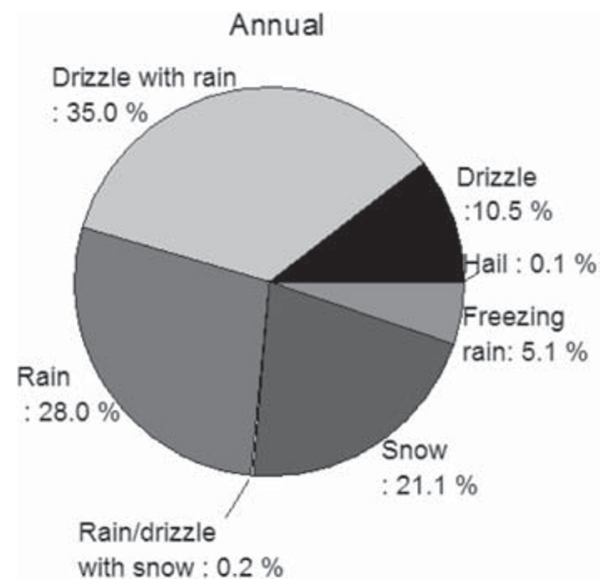

(b)

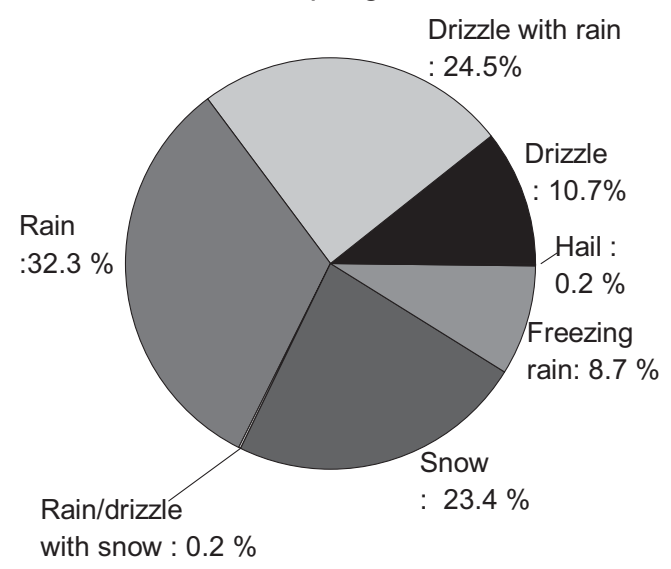

(d) Fall

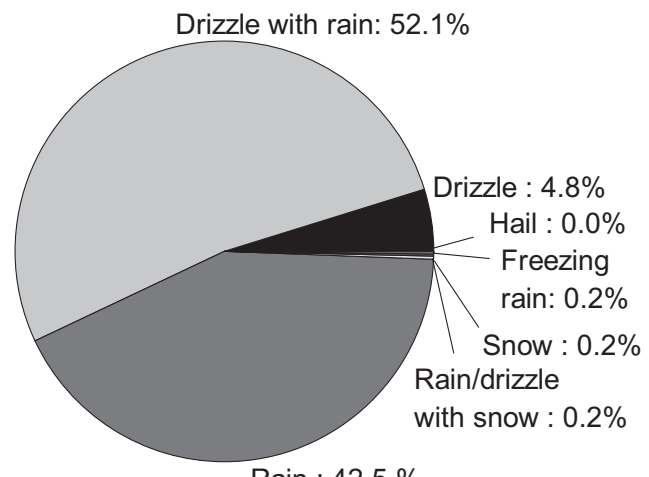

Rain : $42.5 \%$ (c)

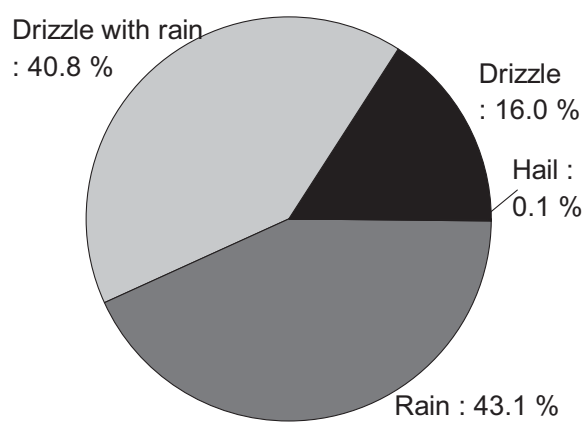

(e)

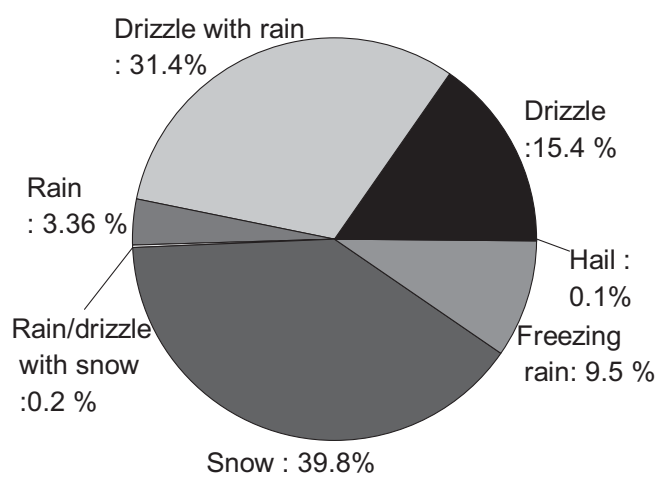

Fig. 3 Seasonal mean occurrence frequencies of hydrometeors from disdrometer measurement at DG from 2010 to 2011: (a) annual, (b) spring, (c) summer, (d) fall, and (e) winter 
remove erroneous data for analyzing $\mathrm{HC}$ and DSD, this study collected only the events with precipitation rate greater than $0.1 \mathrm{~mm} \mathrm{~h}^{-1}$. In particular, the DSD measured by the disdrometer were averaged for one hour to obtain the generalized DSD information from the instrument. The Quality Control (QC) of DSD and $\mathrm{HC}$ data follow the procedures below:

1) Total number of particles: more than 10 drops

2) DSD spectra: this study selected only the spectra where non-zero drop counts were recorded in a series of consecutive channels. The spectra with the largest drop diameter smaller than $0.56 \mathrm{~mm}$ were excluded from the analysis. To remove the dependence on precipitation rate, only the data for limited precipitation rates are selected: specifically $4.5 \mathrm{~mm} \mathrm{~h}^{-1}-5.5 \mathrm{~mm} \mathrm{~h}^{-1}$ and $2.5 \mathrm{~mm} \mathrm{~h}^{-1}-1.5 \mathrm{~mm} \mathrm{~h}^{-1}$ for snow, $4.5 \mathrm{~mm} \mathrm{~h}^{-1}-5.5 \mathrm{~mm} \mathrm{~h}^{-1}$ for rain, and $0.1 \mathrm{~mm} \mathrm{~h}^{-1}-1.0 \mathrm{~mm} \mathrm{~h}^{-1}$ for drizzle.

3) Wind speed: weaker than $10 \mathrm{~m} \mathrm{~s}^{-1}$ (to remove the wind effect error (Friedrich and Higgins 2013))

4) Temperature: Rain and snow data were selected when temperature was warmer than $5{ }^{\circ} \mathrm{C}$ and colder than $0{ }^{\circ} \mathrm{C}$, respectively, to remove drops contaminated by mixed type precipitation.
Fig. 4 Same as Fig. 3 except at MP

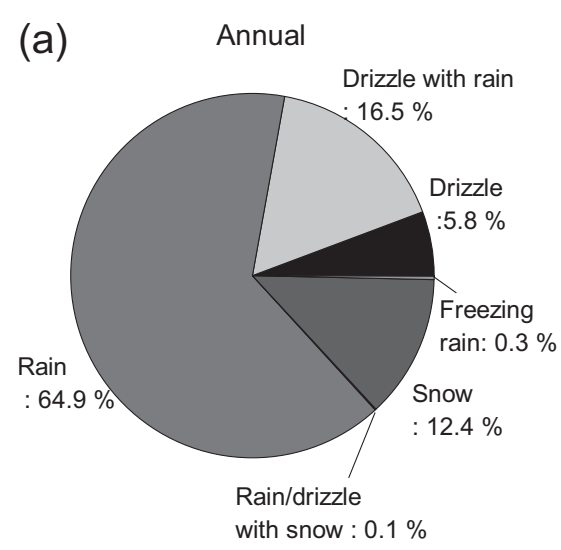

(b)

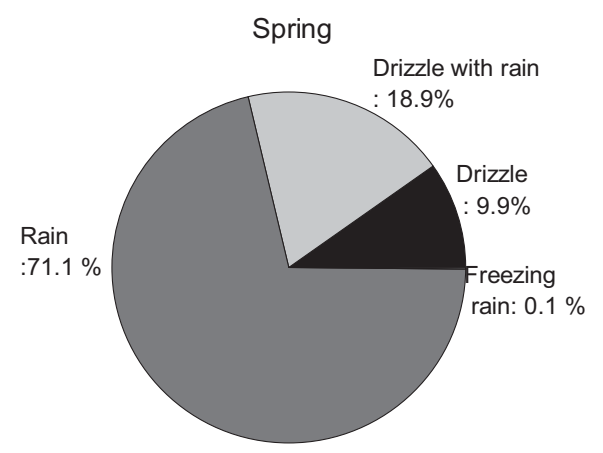

(d)

Fall

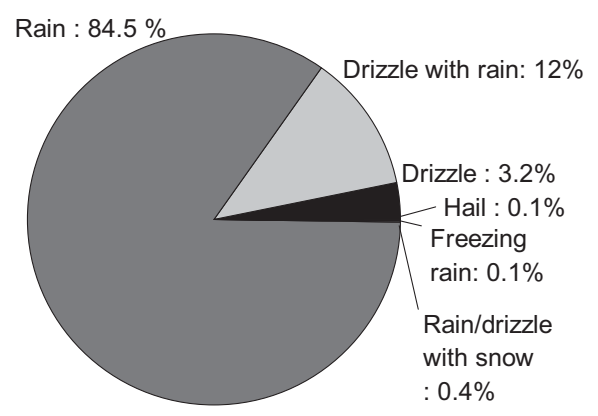

(c)

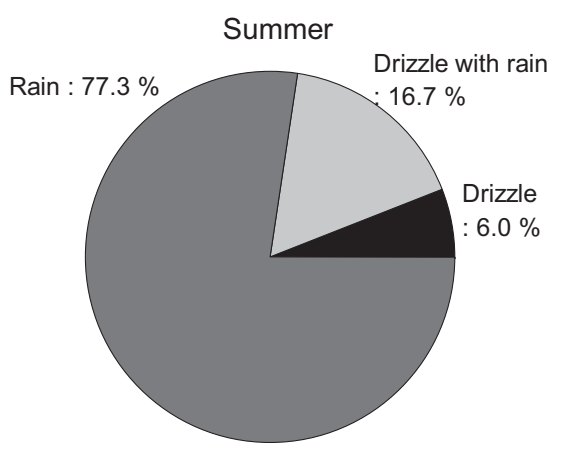

(e)

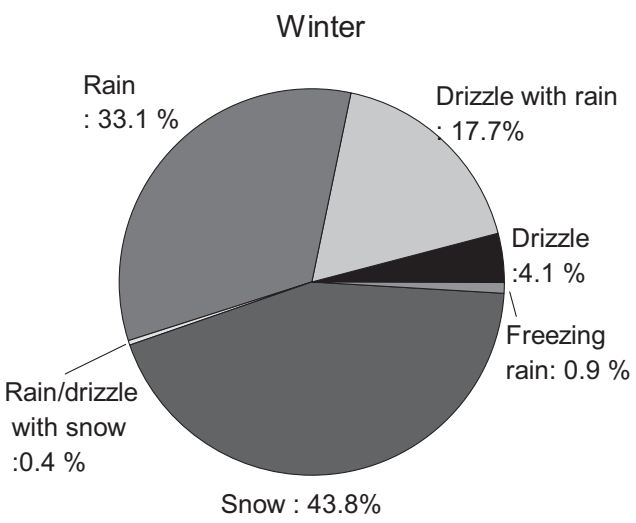


Figure 2 compares the rain rate of the disdrometer with that of the TB rain gauge at the two sites. The $\mathrm{R}^{2}$ (coefficient of determination) was 0.91 at DG. The standard deviations of the collected observational data using by the disdrometer and the $\mathrm{TB}$ rain gauge were $2.07 \mathrm{~mm} \mathrm{~h}^{-1}$ and $1.93 \mathrm{~mm} \mathrm{~h}^{-1}$, respectively, at DG. At MP, the $\mathrm{R}^{2}$ was 0.96 and the standard deviations of the collected observational data were $1.29 \mathrm{~mm} \mathrm{~h}^{-1}$ and $1.35 \mathrm{~mm} \mathrm{~h}^{-1}$, respectively. Similarly, in a previous study, Nam et al. (2008) measured the rain rate with the same two instruments at MP on 22 June 2006 and found that the $\mathrm{R}^{2}$ between the disdrometer and the TB rain gauge was 0.99 for the 30 min averaged rain rate data on that day. The $\mathrm{R}^{2}$ of DG was somewhat smaller than that of MP perhaps because the rain type classification at DG was affected somewhat more significantly by other HCs, such as snow and mixed snow/rain, than that at MP.

To verify the accuracy of the disdrometer $\mathrm{HC}$, the data from an Intensive Observation Period (IOP) in 2010 were analyzed for DG. The HC from weather report at DG were analyzed and then compared with the hourly disdrometer weather codes. For simplicity, the most frequently reported weather code for an hour of $1 \mathrm{~min} \mathrm{HC}$ data are taken as the hourly weather code from the disdrometer. Over the IOP, there were $622 \mathrm{HC}$ events observed by the disdrometer. The human-observed hydrometeor types were generally classified into three types - drizzle, rain, and snow. Therefore, the rest of disdrometer weather codes such as graupel and hail could not be compared with human-observed data for the IOP. Total of 194 precipitation events were selected among the 622 events after QC from. The $\mathrm{HC}$ accuracies of the drizzle, rain, and snow classification by disdrometer were about $87 \%, 95 \%$, and $80 \%$, respectively, while the manufacturer claimed accuracy was $97 \%$ (Table 2). Although the distrometer accuracy was lower than that of the manufacturer, it seemed sufficient enough for studying the HC, DSD, radar application, and so on.

\section{Analysis of DSD Observation in Korea}

\subsection{Analysis of HC Characteristics}

After data QC, the total number of one-minute disdrometer data was 59,200 at DG and 62,593 at MP. Figures 3 and 4 illustrate the seasonal mean occurrence frequency of $\mathrm{HC}$ at DG and MP for 2010-2011: (a) annual, (b) spring, (c) summer, (d) fall, and (e) winter. In the two figures, the contrast of the mountainous (DG) and coastal (MP) regions are clearly displayed. The occurrence frequencies of 'drizzle' and 'drizzle with rain' were $45 \%$ annually and about $57 \%$ in fall at DG. In contrast, at MP, located in a coastal region, 'rain' is dominant. The annual 'rain' occurrence frequency was about $65 \%$ at MP. The 'snow' occurrence frequency was higher at DG with $21 \%$ than at MP with $12 \%$ because DG is at northern latitude and higher altitude than MP. These results indicate that the mountainous site (DG) is affected by the orographic effect that can more easily induce precipitation (Blanchard 1953; Yum and Cha 2010). Supportively, Sun-Hee et al. (2012) showed precipitation enhancement in the DG site area by the orographic effect using numerical modeling. Even without considering the latitude difference, the orographic effect at the mountainous DG site should have enhanced the snowfall amount (Mott et al. 2014).

The HC from the disdrometer measurements at DG and MP are as follows:

1) Drizzle

2) Drizzle with rain

3) Rain

4) Rain and drizzle with snow,

5) Snow

6) Freezing rain

7) Hail
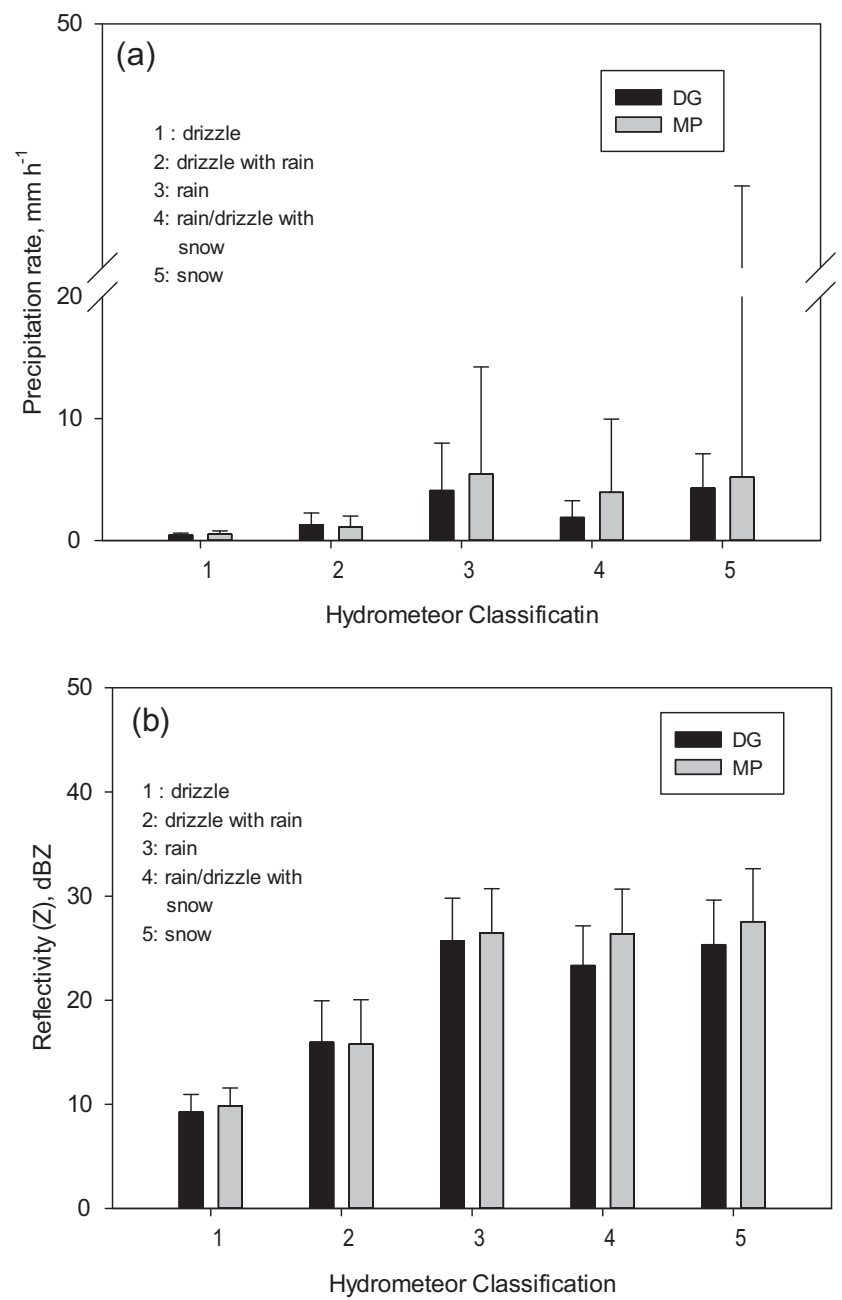

Fig. 5 Mean (a) precipitation rate and (b) reflectivity at DG and MP from 2010 to 2011 for different precipitation types (Vertical bar: mean value, Solid line: standard deviation value) 
The precipitation rate and reflectivity for each $\mathrm{HC}$ were shown in Fig. 5.'Drizzle' and 'Drizzle with rain' exhibited a similar precipitation rate and reflectivity at both sites. For 'rain' and 'snow', the precipitation rate and reflectivity at
Fig. 6 Average (a) drizzle DSD, (b) rain DSD, and (c) snow DSD a tD G a d MP for a fixed range of precipitation rates between

$1.5 \mathrm{~mm} \mathrm{~h}^{-1}$ and $2.5 \mathrm{~mm} \mathrm{~h}^{-1}$ for snow, between $4.5 \mathrm{~mm} \mathrm{~h}^{-1}$ and $5.5 \mathrm{~mm} \mathrm{~h}^{-1}$ for rain, and between $0.0 \mathrm{~mm} \mathrm{~h}^{-1}$ and $1.0 \mathrm{~mm} \mathrm{~h}^{-1}$ for drizzle
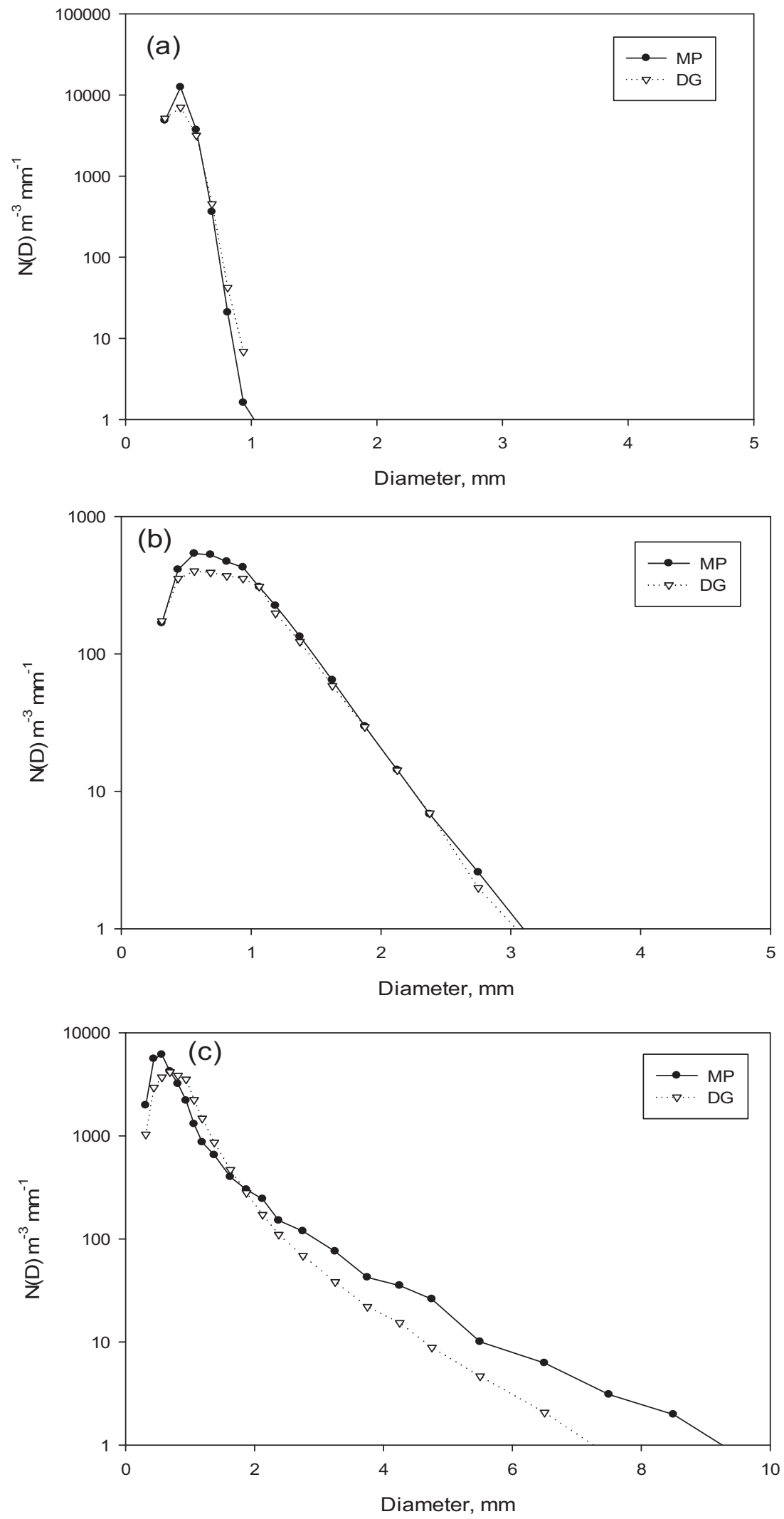
MP were larger by about $1 \mathrm{~mm} \mathrm{~h}^{-1}$ and $1 \mathrm{dBZ}$ than those at DG. Mixed phase, 'rain and drizzle with snow', produced relatively large differences between DG and MP. The human weather reports did not record hail at both sites during the study period (2010-2011). However, the disdrometer classified about $0.1 \sim 0.2 \%$ of total observation as 'hail' at both sites (Figs. 3 and 4). Most of 'wet snow' recorded by human weather reports were classified as 'hail' by the disdrometer. On the other hand, the disdrometer classified about $0.1 \sim 9.5 \%$ of total observation as 'freezing rain' at both sites (Figs. 3 and 4), while the human weather reports did not record 'freezing rain' at both sites. Therefore, this study did not included 'freezing rain' and 'hail' data in Fig. 5. Especially, there was a large standard deviation in 'snow' observation at MP in Fig. 5a because the snow rate was largely varied by meteorological fluctuation of coastal regions in KOREA such as CAPE (Convective Available Potential Energy) and temperature (Cha et al. 2009) .

\subsection{Characteristics of DSD}

DSD data are important because they provide the basic information necessary for understanding precipitation type and amount. Only the three HC, drizzle, rain, and snow, were selected and their DSD were analyzed. The DSD for the fixed precipitation rates of $1 \mathrm{~mm} \mathrm{~h}^{-1}$ for drizzle, $5 \mathrm{~mm} \mathrm{~h}^{-1}$ for rain, and $5 \mathrm{~mm} \mathrm{~h}^{-1}$ for snow were compared for DG and MP. The maximum drop number density occurred between 0.4 to $0.5 \mathrm{~mm}$ diameter for drizzle and 0.6 to $1 \mathrm{~mm}$ diameter for rain and snow. The rain DSD was mainly observed below $3 \mathrm{~mm}$ diameter when drop number density was more than $1 \mathrm{~m}^{-3} \mathrm{~mm}^{-1}$ at DG. For snow DSD, the N(D) was found to be limited below $8 \mathrm{~mm}$ diameter at DG. The drizzle and rain
DSD observed at DG and MP were very similar (Fig. 6a and b). The maximum drop number density was at 0.4 to $0.5 \mathrm{~mm}$ diameter. The differences of drizzle and rain DSD between DG and MP occurred at $1 \mathrm{~mm}$ diameter and 0.6 to $1 \mathrm{~mm}$ diameter, respectively. DG had a slightly higher maximum drop number density than that of MP at this diameter. That is, mountainous terrain near DG forces the airflow to ascend and then initiates the formation of precipitation such as the results of Cosma et al. (2002). The particle number density of snow at MP (Fig. 6c) was significantly higher than that of DG above $2 \mathrm{~mm}$ diameter. This means that it was easier for large snow particles to form at MP than at DG probably because convective precipitation occurred more frequently at the coastal region (MP) than at the mountain region (DG). The mean values of total number density were $6148 \mathrm{~m}^{-3} \mathrm{~mm}^{-1}$ at MP and $3705 \mathrm{~m}^{-3} \mathrm{~mm}^{-1}$ at DG at $0.6 \mathrm{~mm}$ diameter and $10 \mathrm{~m}^{-3} \mathrm{~mm}^{-1}$ at MP and $5 \mathrm{~m}^{-3} \mathrm{~mm}^{-1}$ at DG at $5.5 \mathrm{~mm}$ diameter (Fig. 6c).

\subsection{Temperature, Wind Speed, and Wind Direction Effects on DSD}

Weather conditions are important factors that affect DSD. Rain and drizzle DSD varied little with temperature variation, while snow DSD was affected significantly by temperature variation. Most studies of snow DSD used aircraft data and compared the temperature and snow types (e. g., Jeck (1998)). Even though this study used ground-based measurement, long term snow DSD clearly shows strong dependence on the weather conditions at the measurement site well.

In particular, snow properties depend on temperature. Heymsfield et al. (2013) studied characteristics of ice particle distributions and pressure-dependent terminal velocities from
Fig. 7 Average DSDs of snow particles at DG and MP at specific temperature range ranges ($5{ }^{\circ} \mathrm{C} \sim 0{ }^{\circ} \mathrm{C},-10{ }^{\circ} \mathrm{C} \sim-5^{\circ} \mathrm{C}$; a fixed range of precipitation rate between $4.5 \mathrm{~mm} \mathrm{~h}^{-1}$ and $5.5 \mathrm{~mm} \mathrm{~h}^{-1}$ )

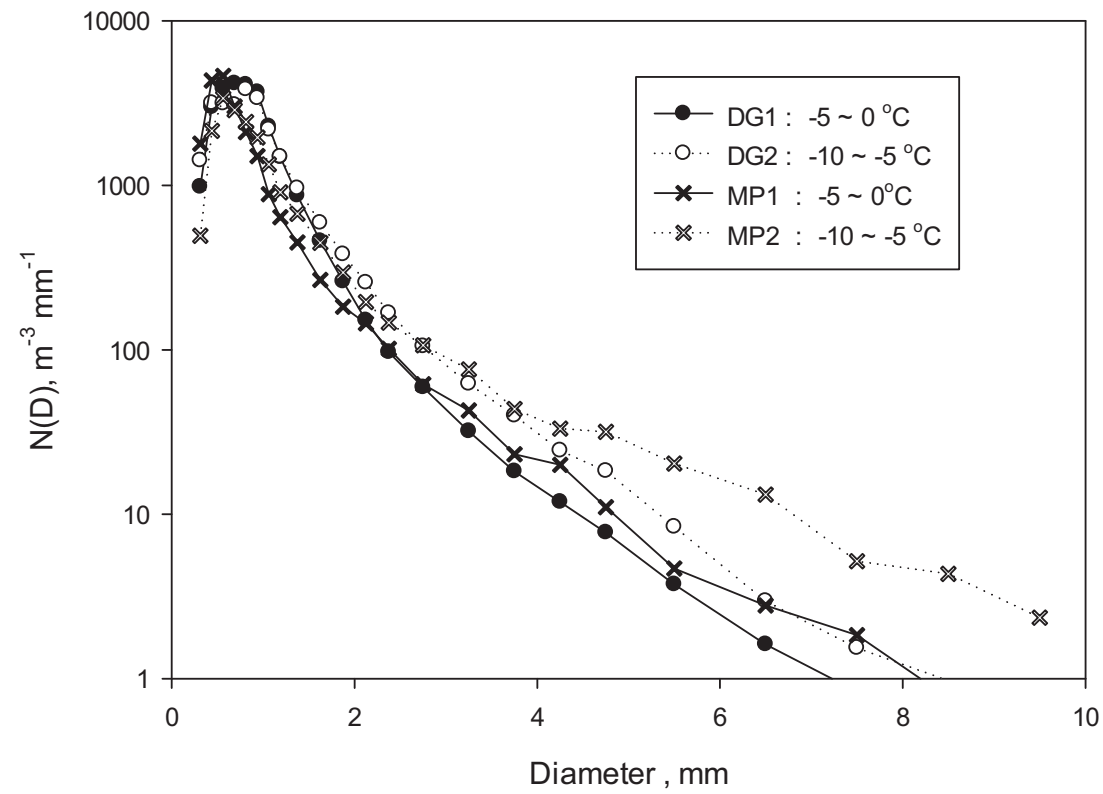


in-situ observations of clouds at a temperature range of $0{ }^{\circ} \mathrm{C}$ to $-86^{\circ} \mathrm{C}$. The ice particle size distributions were found to be nearly exponential at temperatures from about $-40{ }^{\circ} \mathrm{C}$ to $-10{ }^{\circ} \mathrm{C}$. Snow DSDs of this study were similar to the ice particle size distributions from aircraft measurement by Heymsfield et al. (2013) at temperatures from $0{ }^{\circ} \mathrm{C}$ to $-20{ }^{\circ} \mathrm{C}$. Woods et al. (2008) observed the size spectra of snow particles measured in wintertime precipitation. They showed that the size spectra at $-3{ }^{\circ} \mathrm{C}$ had higher drop number concentration than that at $-7{ }^{\circ} \mathrm{C}$. Wind speed and direction were also necessary information to understand precipitation DSD. The DG and MP sites were also affected by the continental and maritime precipitation according to the wind direction.
To see the temperature effect, this study considered three specific temperature ranges for DG (i. e. DG1:- $5^{\circ} \mathrm{C}$ to $0{ }^{\circ} \mathrm{C}$, DG2:- $10{ }^{\circ} \mathrm{C}$ to $-5{ }^{\circ} \mathrm{C}$ ) and two for MP (i. e. MP1: $-5{ }^{\circ} \mathrm{C}$ to $0{ }^{\circ} \mathrm{C}$, MP2: $-10^{\circ} \mathrm{C}$ to $-5^{\circ} \mathrm{C}$ ) for a fixed precipitation rate range of $4.5-5.5 \mathrm{~mm} \mathrm{~h}^{-1}$ for snow. Figure 7 compares snow particle size distributions for different temperature ranges. The total concentration, which is dominated by small particles (diameter $<1 \mathrm{~mm}$ ), tends to be higher for warmer temperature. More importantly, the proportion of larger particles (diameter $>$ $1 \mathrm{~mm}$ ) in comparison to that of small ice particles decreases as temperature becomes warmer. This is contrary to previous observations by Harimaya and Kawasato (2001) and Yuter et al. (2006), which showed that in warmer temperature, the number density of large snow particles decreased while the
Fig. 8 Average DSD of snow particles for specific wind speed ranges (a) at DG and (b) at MP; a fixed range of precipitation rate between $4.5 \mathrm{~mm} \mathrm{~h}^{-1}$ and $5.5 \mathrm{~mm} \mathrm{~h}^{-1}$ )
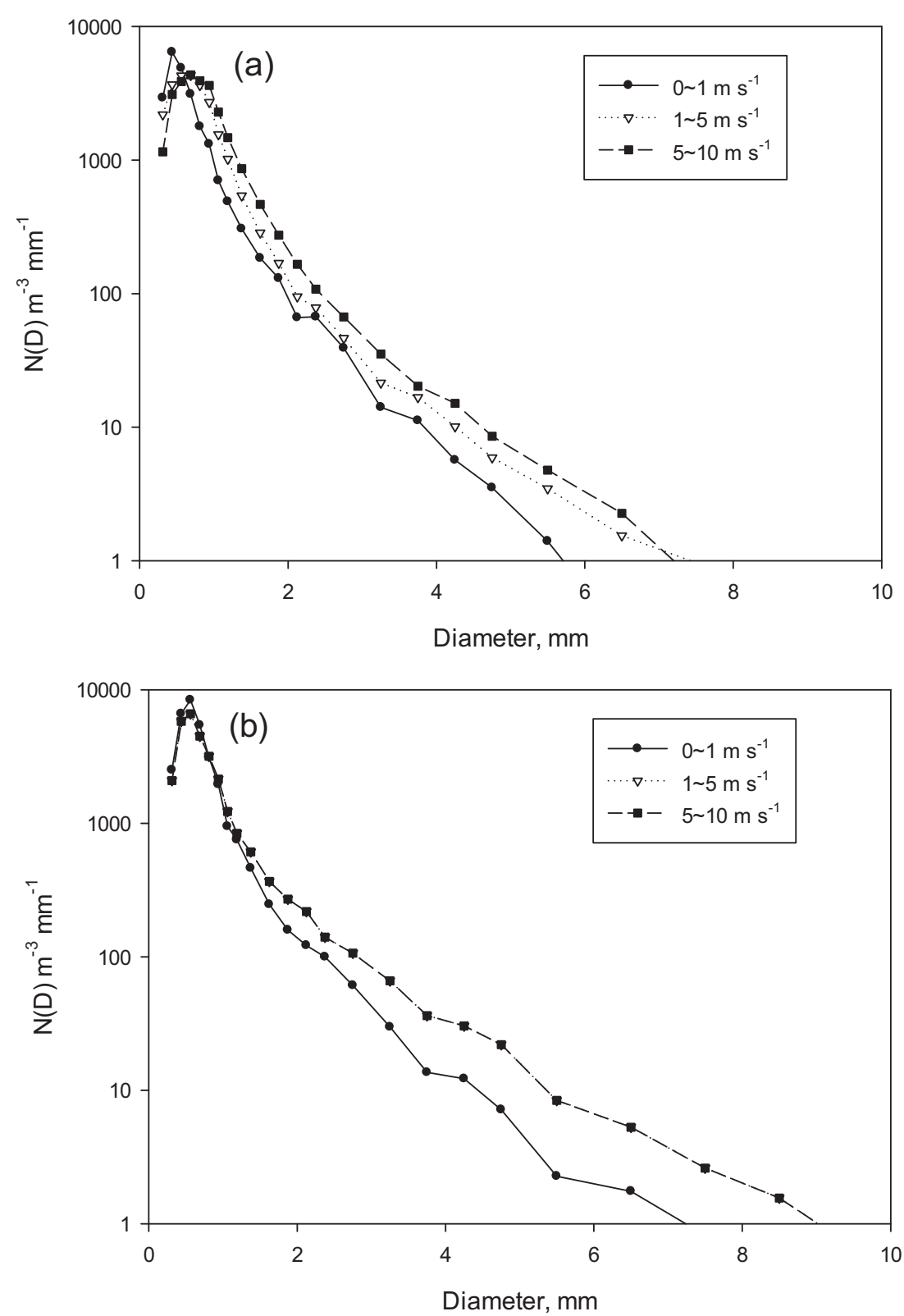
number density of small snow particles increased, mainly due to aggregation. Such contrary results in our observation may suggest that aggregation was not very efficient in our observation. Instead riming may have been the major mechanism of producing large snow particles, which would be relatively more efficient at colder temperature than aggregation is. These results demonstrate the strong relationship between
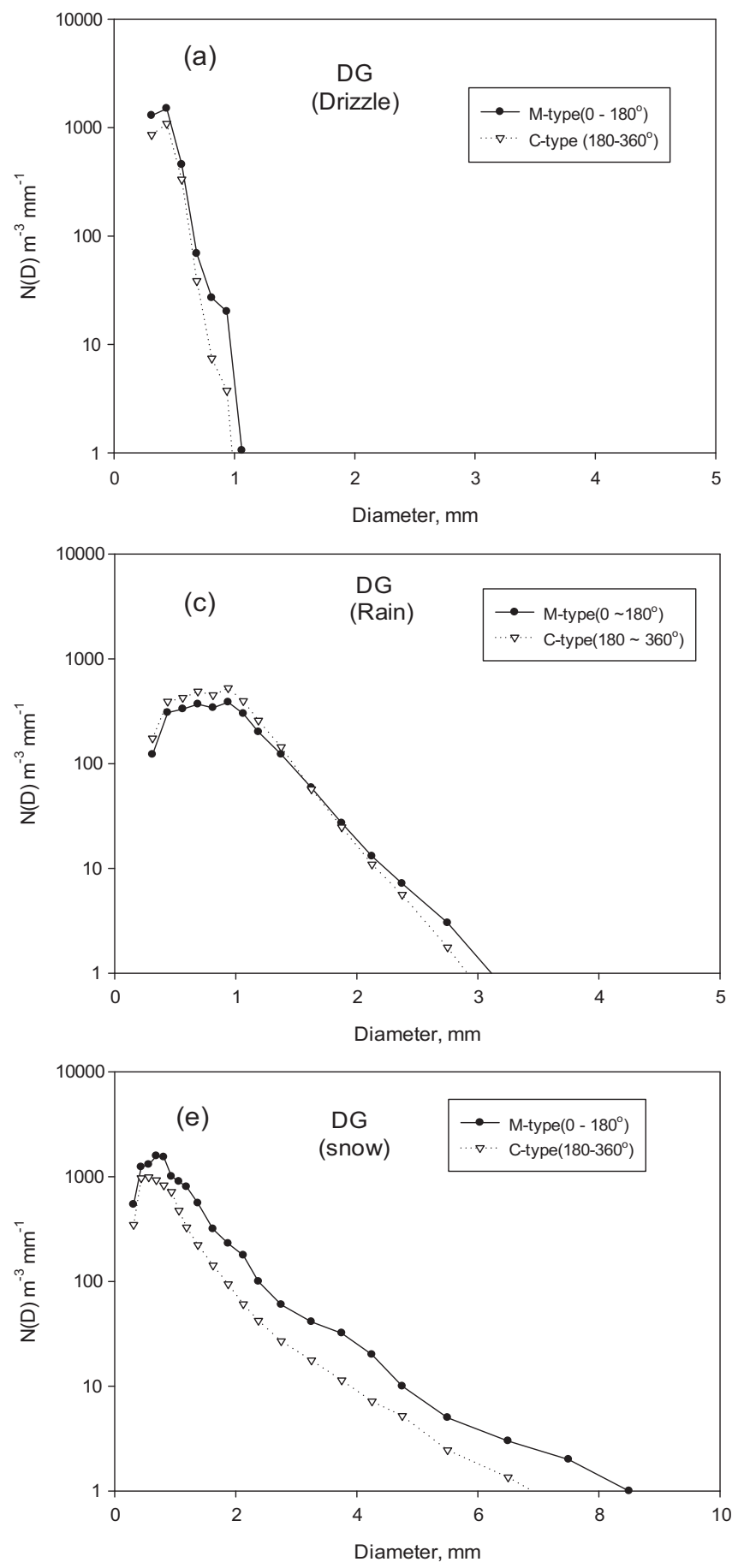

Fig. 9 Comparison of mean drizzle DSD (a) at DG and (b)MP, mean rain DSD (c) at DG and (d) MP (b), and mean snow DSD (e) at DG and (f) MP for a fixed range of precipitation rates between $1.5 \mathrm{~mm} \mathrm{~h}^{-1}$ and temperature and microphysical processes of aggregation and riming. Another factor affecting the snow particle number density is vapor pressure and supercooled water amount. However, vapor pressure was not observed in this study.

To see wind speed effects, the wind speed was classified into three ranges (i. e. $0 \mathrm{~m} \mathrm{~s}^{-1}$ to $1 \mathrm{~m} \mathrm{~s}^{-1}, 1 \mathrm{~m} \mathrm{~s}^{-1}$ to $5 \mathrm{~m} \mathrm{~s}^{-1}, 5 \mathrm{~m} \mathrm{~s}^{-1}$ to $10 \mathrm{~m} \mathrm{~s}^{-1}$ ). Drizzle and rain DSD were affected little by wind
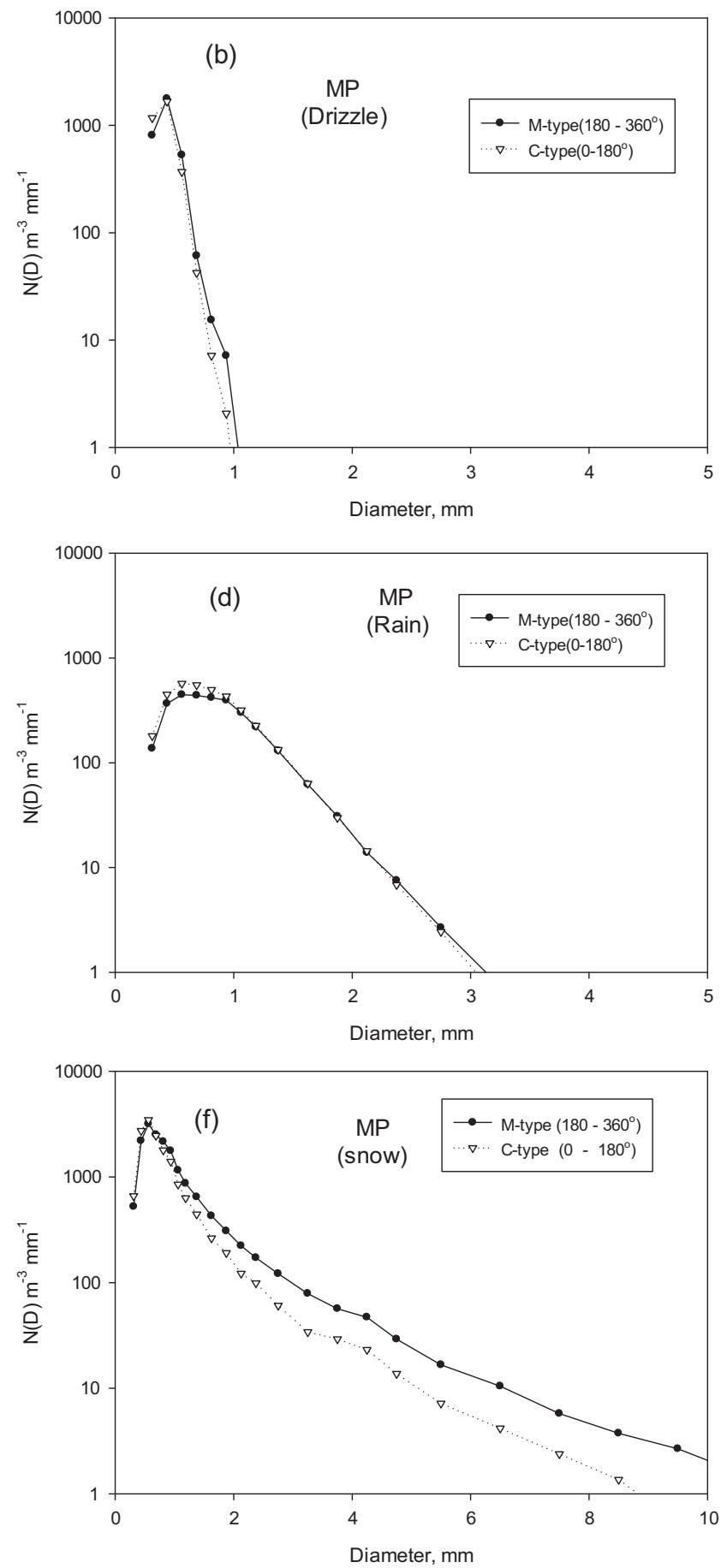

$2.5 \mathrm{~mm} \mathrm{~h}^{-1}$ for snow, between $4.5 \mathrm{~mm} \mathrm{~h}^{-}$land $5.5 \mathrm{~mm} \mathrm{~h}^{-1}$ for rain, and between $0.0 \mathrm{~mm} \mathrm{~h}^{-1}$ and $1.0 \mathrm{~mm} \mathrm{~h}^{-1}$ for drizzle 
Table 3 Rain DSD parameters in DG and MP (Gamma DSD, Caracciolo, 2006)

\begin{tabular}{clll}
\hline & $\begin{array}{l}\mathrm{N}_{0} \\
\left(\mathrm{~m}^{-3} \mathrm{~mm}^{-1}\right)\end{array}$ & $\mathrm{m}$ & $\Lambda\left(\mathrm{mm}^{-1}\right)$ \\
\hline $\mathrm{DG}(\mathrm{M})$ & $7.6 \times 10^{3}$ & 1.3 & 3.4 \\
$\operatorname{DG}(\mathrm{C})$ & $2.6 \times 10^{3}$ & 2.1 & 4.4 \\
MP (M) & $5.6 \times 10^{3}$ & 0.7 & 3.0 \\
$\operatorname{MP}(\mathrm{C})$ & $1.0 \times 10^{4}$ & 1.2 & 3.5 \\
\hline
\end{tabular}

$* \mathrm{~N}_{0}$ : a concentration parameter, $\mathrm{m}$ : a shape parameter, $\Lambda$ : a scale parameter

*(M): Maritime precipitation type, (C): Continental precipitation type

speed (not shown) but snow DSD showed relatively large variation (See Fig. 8). Ware et al. (2006) showed that the snow density (ratio of snow mass to total hydrometeor mass) increased from about $10 \%$ at low wind speed $\left(2 \sim 3 \mathrm{~m} \mathrm{~s}^{-1}\right)$ to about $20 \%$ at $9 \mathrm{~m} \mathrm{~s}^{-1}$. They insisted that the snow density usually depended on snow particle aggregation since most large snow particles were formed by aggregation. Harimaya and Kawasato (2001) also indicated that the aggregation effect on snowfall rate increase was larger for stronger winds. In our observation, however, riming should also have affected significantly as we speculated just above. We do see in Fig. 8 that the number density for $0 \mathrm{~m} \mathrm{~s}^{-1}$ $1 \mathrm{~m} \mathrm{~s}^{-1}$ wind speed is higher than that for $5 \mathrm{~m} \mathrm{~s}^{-1}-10 \mathrm{~m} \mathrm{~s}^{-1}$ from 0.6 to $1 \mathrm{~mm}$ diameter and the snow particle size tends to increase as wind speed increases.

Based on wind direction, precipitation can be classified into continental and maritime types (Rosenfeld an and Ulbrich 2003). Muller et al. (2010) showed that continental precipitation had low rainwater and the DSD contained fewer, smaller droplets. Borys et al. (2003) showed that riming of cloud drop in continental polluted clouds was light but heavier riming occurred in non-polluted clouds. DG and MP are located at a mountainous and a coastal region, respectively. Therefore, the precipitation properties at the two sites can be classified into maritime and continental precipitation types according to wind direction. There were also regional characteristics at DG and MP that may depend on wind direction such as rainwater and supercooled drops (Cha et al. 2007).

In this study, the maritime precipitation type is dominant for wind directions from $0^{\circ}$ to $180^{\circ}$ while the continental precipitation type is dominant for wind directions from $180^{\circ}$ to $360^{\circ}$ at DG. At MP, it is the opposite: the maritime type (Mtype) wind direction was $180^{\circ}$ to $360^{\circ}$ while the continental type (C-type) wind direction was $0^{\circ}$ to $180^{\circ}$ (Fig. 1 ). To remove the effect of precipitation rate, only the fixed precipitation rate range of 1.5-2.5 $\mathrm{mm} \mathrm{h}^{-1}$ for snow, 4.5-5.5 $\mathrm{mm} \mathrm{h}^{-1}$ for rain, and $0.0-1.0 \mathrm{~mm} \mathrm{~h}^{-1}$ for drizzle were examined. The occurrence frequencies of $\mathrm{M}$-type and $\mathrm{C}$-type snow precipitation at DG were $67 \%$ and $33 \%$, respectively, when classified by wind direction. At MP, the frequency rate was similar to that at $\mathrm{DG}$.

Figure 9 compares snow DSD at the temperature of $-10^{\circ} \mathrm{C}$ for continental and maritime types. N(D) is higher for most of the size range in M-type than in C-type precipitation at both sites but especially more for DG. Snow N(D) of M-type at DG increased most noticeably at 0.6 to $1 \mathrm{~mm}$ diameter compared to other diameters. The N(D) for the $0.6 \mathrm{~mm}$ to $1 \mathrm{~mm}$ diameter in M-type was 10 times higher than that in C-type at DG (Fig. 9a). At MP, the snow N(D) was similar between Mtype and C-type around 0.6 to $1 \mathrm{~mm}$ diameter but the $\mathrm{N}(\mathrm{D})$ of M-type was higher than that of C-type at the larger diameter range. These results suggest that DG is mainly affected by the orographic effect around 0.6 to $1 \mathrm{~mm}$ diameter while the effect was weak for the same diameters at MP (Yum and Cha 2010; Cha et al. 2009). However, the difference of snow N(D) between M-type and C-type at MP was larger than that at DG for the 5-10 $\mathrm{mm}$ diameter range. The results of difference of snow N(D) at MP and DG were similar to those of previous studies (Harimaya and Sato 1989, 1992); Harimaya and Kanemura (1995) in coastal regions. In addition, we analyzed the characteristics of gamma rain DSD parameters of such as the concentration parameter $\left(\mathrm{N}_{0}\right)$, the shape parameter $(\mathrm{m})$, and the scale parameter $(\Lambda)$ of M-type and C-type in DG and MP (Table 3 ). The values of $\mathrm{N}_{0}, \mathrm{~m}$, and $\Lambda$ of M-type were higher than those of C-type. Such contrast means that the number of rain drops of C-type is greater than that of M-type,
Fig. 10 (a) A high resolution camera for a manual snow type measurement and (b) a photo example of the snow type taken by the camera (February 1, 2010) (a)

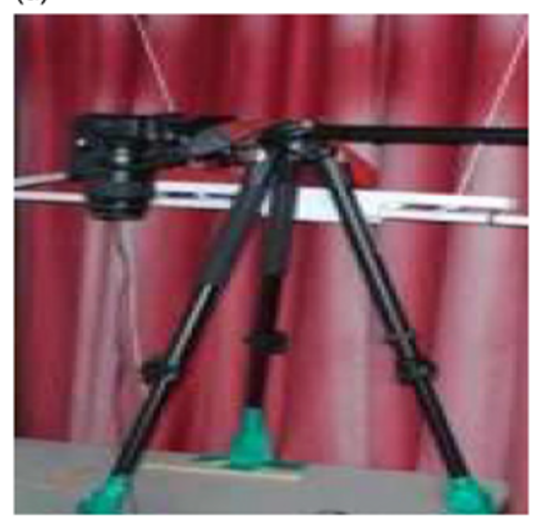

(b)

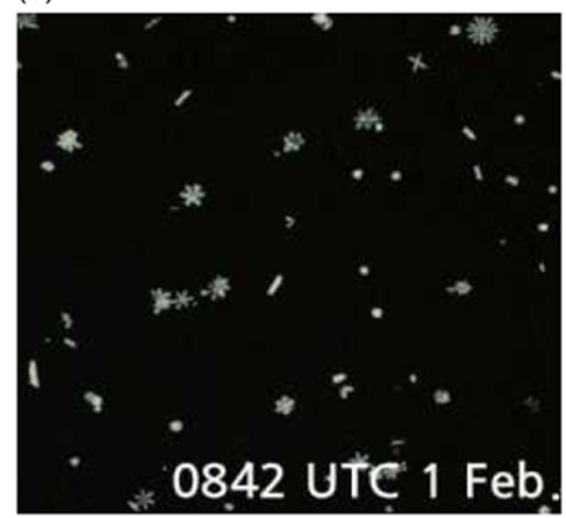


while the size of rain drops of C-type is smaller than that of Mtype.

\subsection{Case Studies of Camera-Observed Snow Particle Types}

A manual snow type measurement device that utilized a high resolution camera was installed at DG for 8 days in January and March 2010. A black velvet fabric-packed panel was used for sampling snow particles (Fig .10). The total period of measurement was $41 \mathrm{~h}$ with a total number of observations of 400 .

Figure 11a and $b$ show the occurrence frequencies of snow particle types and microphysical processes. Figure 11c compares the mean temperature, wind speed, and reflectivity of disdrometer for each snow particle type. Figure 11d compares snow DSD of the plate and column types. It is shown that the mixed type of plate and column was the most frequently observed at DG. With regard to microphysical processes for the snow particles, aggregation is generally considered to be the dominant growth process for large snow particles (Field 1999).
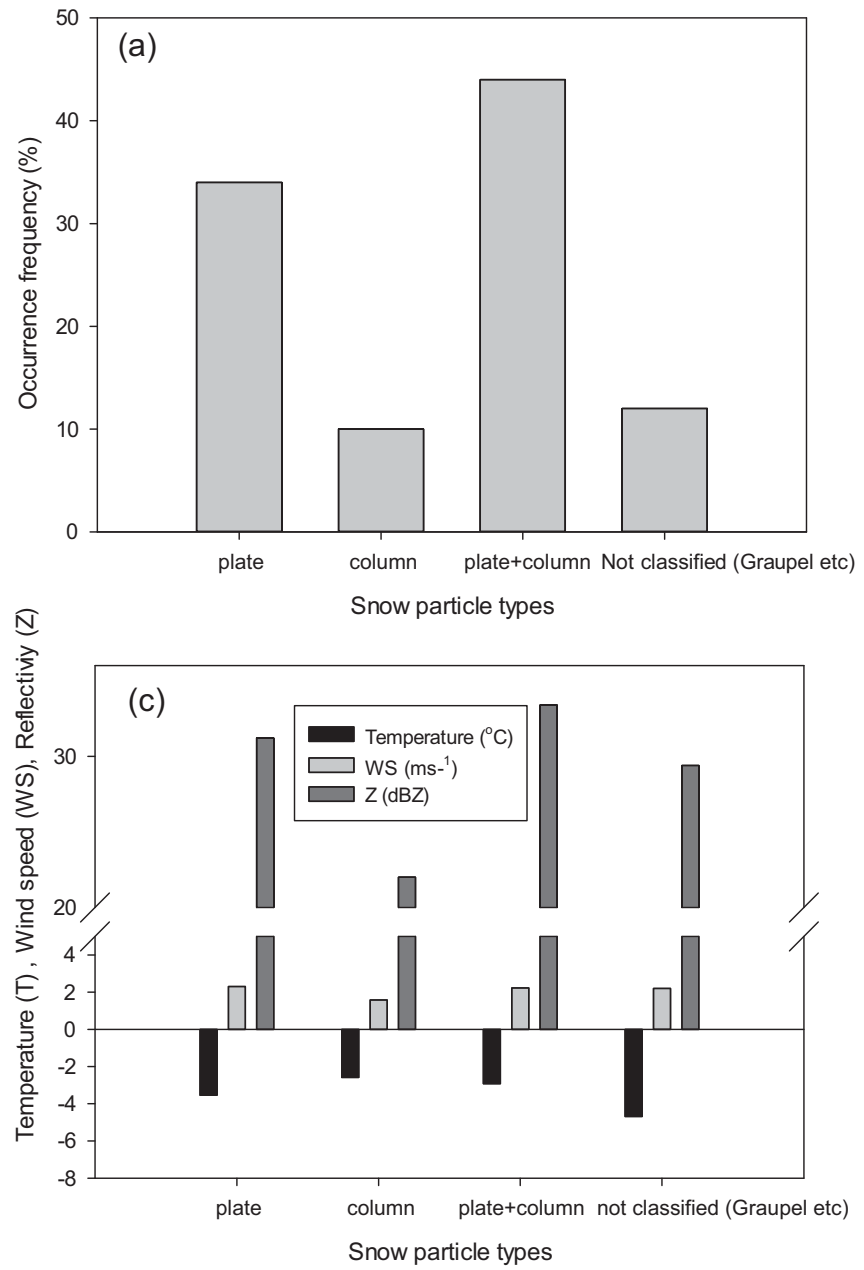

Fig. 11 Snow particle type classification of the camera measurement data for 8 days between January and March, 2010. (a) occurrence frequency, (b) associated microphysical processes, (c) temperature, wind speed, and
According to camera observation data, aggregation and riming mainly occurred at plate and riming snow particles, respectively. Aggregation and riming simultaneously affected the snow particles in the mixed type of plate and column (Fig. 11 b). The unclassified type (usually graupel) occurred at the lowest mean temperature, about $-5^{\circ} \mathrm{C}$. The plate type occurred at relatively lower temperatures than those of column type (Fig. 11c). The results were similar to those of Nakaya and Sekido (1936) and Woods et al. (2008). Nakaya and Sekido (1936) observed the snow particle types by ground instrument and Woods et al. (2008) measured them by aircraft. The retrieved reflectivity from the disdrometer was the lowest for column type while that of the mixed type was relatively high (Fig. 11c). The snow particle number density was higher but the DSD was steeper for the column type than for the plate type (Fig. 11d). In future studies, the microphysical processes in the relation to snow particle type need to be further investigated since the type of snow particle observed was greatly affected by local weather conditions such as supercooled water and temperature.
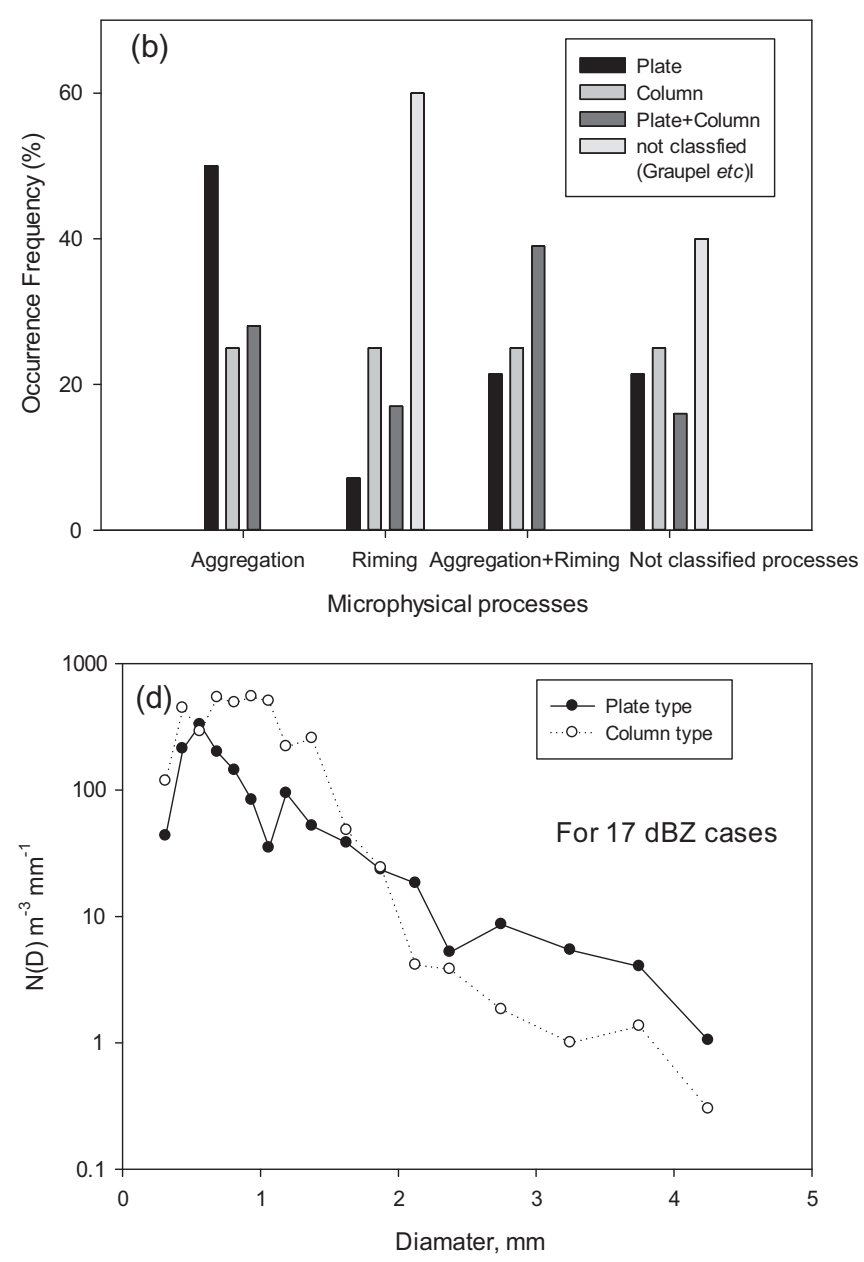

reflectivity for each snow particle type, and (d) average DSD for plate and column type of snow particle precipitation with $17 \pm 1 \mathrm{dBZ}$, reflectivity 
(a)
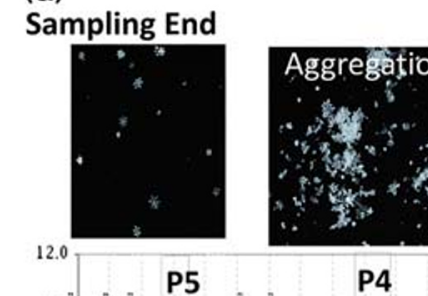

1
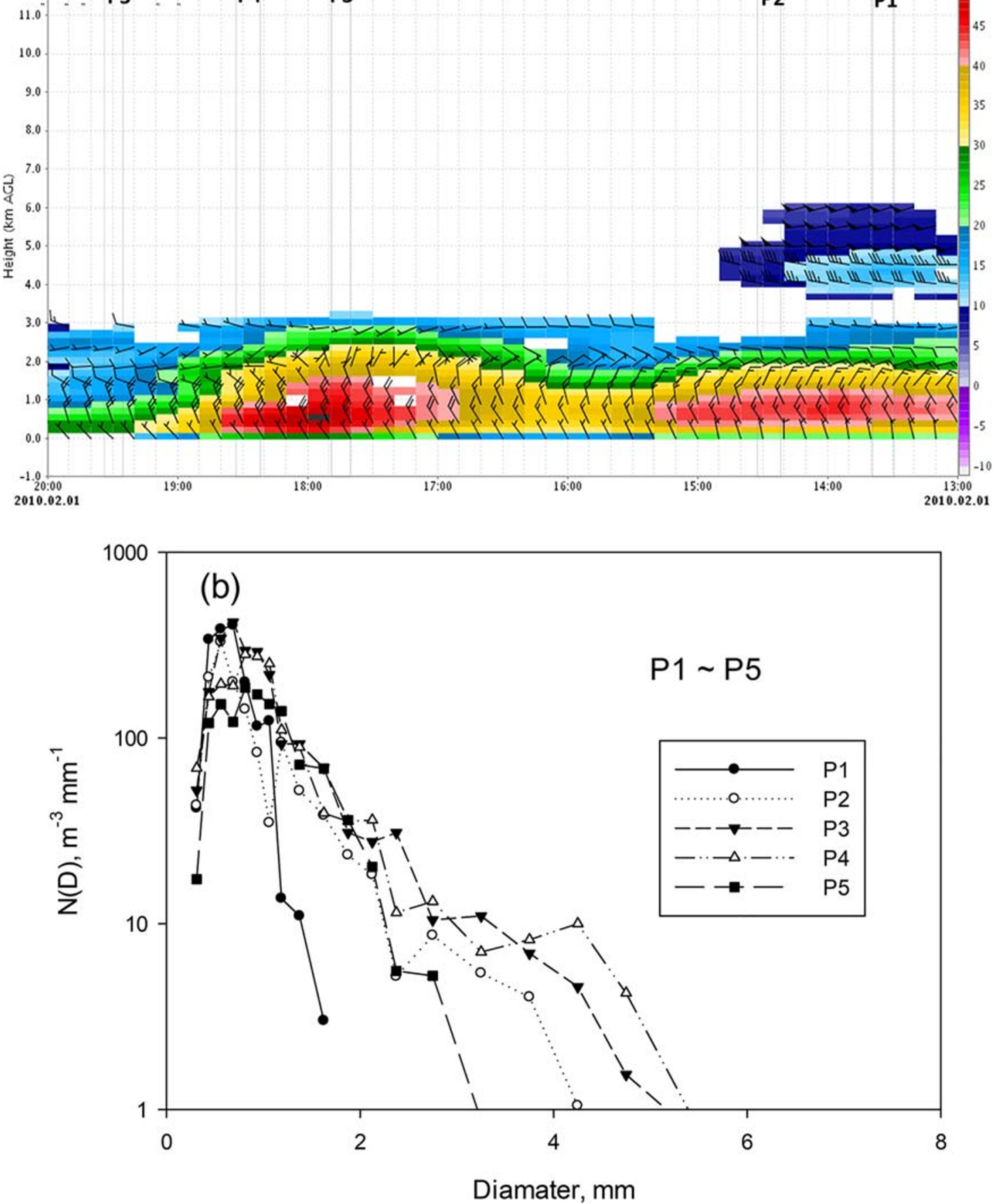

Fig. 12 Comparison of (a) wind profiler data with the camera-observed snow measurement data and (b) snow particle size distributions in P1 to P5 at DG on 1 February 2010 
Fig. 13 Examples of ice microphysical process observed data at DG on 1 February 2010 classification for the camera
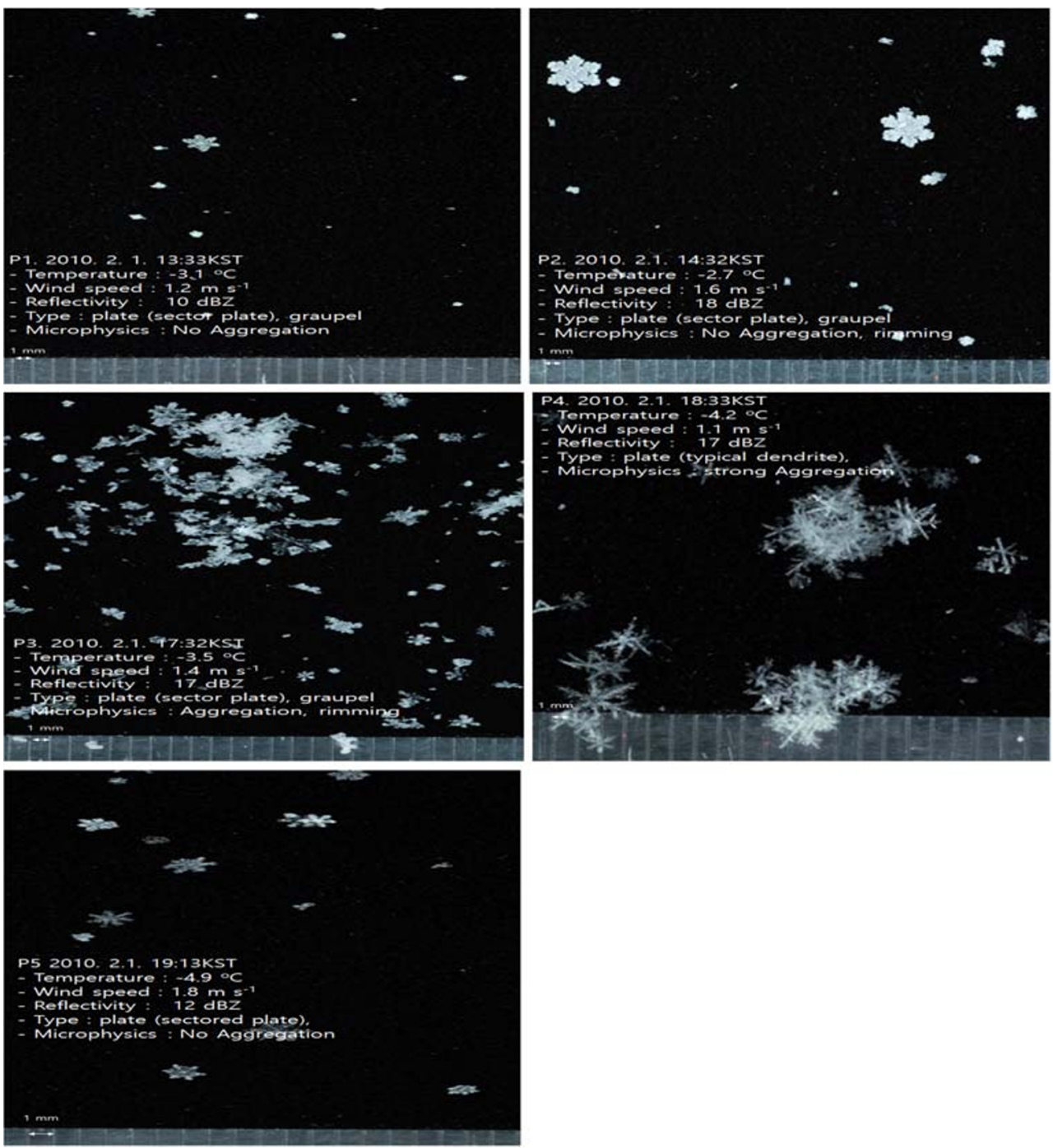

In Fig. 12 and Fig. 13, snow DSD from the disdrometer is compared with the data of the humanobserved snow type measurement during a snow event; P1, sampling start, to P5, sampling end. Aggregation occurred at P3 and P4. Most aggregation occurred for plate type. This results suggest that the aggregation typically influence the reduction of snow particle number concentration for diameter smaller than $1 \mathrm{~mm}$ and the increase of them above $5 \mathrm{~mm}$ in diameter at P3 and P4 when compared with that at P1 and P2. The aggregation and riming effect on snow DSD should be analyzed by using a more precise instrument such as a 2DVD (2 Dimension Video Disdrometer) because the long-term observation of snow particle type and size can clearly show the relationship of the microphysical processes and the hydrometer size distribution. In future studies, we need to investigate the relation between reflectivity and snow particle types if more accurate instruments are available for snow particle type such as MASC (Multi-Angle Snowflake Camera).

\section{Conclusion}

Our results provide unique information on the HC and DSD and the basic microphysical effects on HC and DSD - something rarely studied in Korea. Distinctly different shapes of DSD at DG and MP were observed in snow events but not drizzle and rain events. Larger snow particles were formed at MP since convective precipitation occurs more frequently at the coastal site (MP) than in the mountain site (DG).

In our dataset, the temperature effect showed that the relatively warm temperature (from $-5{ }^{\circ} \mathrm{C}$ to $-0{ }^{\circ} \mathrm{C}$ ) increased the snow $\mathrm{N}(\mathrm{D})$ at around $0.6 \mathrm{~mm}$ diameter and the relatively cold temperature(from $-15{ }^{\circ} \mathrm{C}$ to $10{ }^{\circ} \mathrm{C}$ ) decreased the $\mathrm{N}(\mathrm{D})$ above $2 \mathrm{~mm}$ diameter. For the wind speed effect, rain and drizzle were less sensitive to wind speed than snow. It is suggest that snow particles may produce large particles more easily when wind is strong. However, wind speed effect for snow particle size distribution has a lot of uncertain factors. So, we need to study more detailed measurement techniques for comparison of wind speed and snow particle sizes in future studies. 
It is very rare study case in Korea to compare the snow particle type observation by manual camera with that of a parsivel disdrometer at a mountain site (DG). From the results of the comparison, the mixed type of plate and column was the most frequent and aggregation frequently occurred for plate type. Aggregation and riming simultaneously affected the snow particles in the mixed type of plate and column. At lower temperature type, the plate type occurred more frequently than the column type. The reflectivity was the lowest for column type.

The reflectivity of mixed type was relatively high. The microphysical processes related to the results will need to be further investigated since the formation of snow particle type was greatly affected by local weather conditions such as supercooled water and specific temperature. In the future, the snow DSD should be studied simultaneously with a instrument that can identify microphysical process clearly, such as a 2DVD.

Acknowledgements This work was funded by the Korea Meteorological Administration Research and Development Program "Development of Application Technology on Atmospheric Research Aircraft (1365003069)" and we thank Gyu Won Lee for providing data about camera-observed snow particle images.

Open Access This article is licensed under a Creative Commons Attribution 4.0 International License, which permits use, sharing, adaptation, distribution and reproduction in any medium or format, as long as you give appropriate credit to the original author(s) and the source, provide a link to the Creative Commons licence, and indicate if changes were made. The images or other third party material in this article are included in the article's Creative Commons licence, unless indicated otherwise in a credit line to the material. If material is not included in the article's Creative Commons licence and your intended use is not permitted by statutory regulation or exceeds the permitted use, you will need to obtain permission directly from the copyright holder. To view a copy of this licence, visit http://creativecommons.org/licenses/by/4.0/.

\section{References}

Battaglia, A., Rustemeier, E., Tokay, A., Blahak, U., Simmer, C.: PARSIVEL snow observation: a critical assessment. J .of Atomspheric and Oceanic Technology. 27, 333-344 (2010)

Blanchard, D.C.: Raindrop size-distribution in Hawaiian rains. J. Meteorol. 10, 457-473 (1953)

Borys, S.D., Lowenthal, D.H., Cohn, S.A., Brown, W.O.J.: Mountaontop and radar measurements of anthropogenic aerosol effects on snow growth and snow rate. Geophys. Res. Lett. 30, 1538-1542 (2003)

Caracciolo, C., Prodi, F., Battaglia, A., Porcu, F.: Analysis of the moments and parameters of a gamma DSD to infer precipitation properties: a convective stratiform discrimination algorithm. Atmos. Res. 80, 165-186 (2006)

Cha, Joo Wan, Seong Soo Yum and Ki-Ho Chang, 2007: Characteristics of cloud microphysical properties at the cloud Physcial observation Ysstem (CPOS) site in Korea. 2007 Fall meeting of American Geophysical Union, 913

Cha, J.W., Chang, K.-H., Yum, S.S., Choi, Y.-J.: Comparison of the bright band characteristics measured by micro rain radar (MRR) at a mountain and a coastal site in South Korea. Advences in Atmospheric Sciences. 26, 211-221 (2009)
Cha, J.W., Chang, K.H., Oh, S.N., Choi, Y.J., Jeoung, J.Y., Jung, J.W., Yang, H.Y., Bae, J.Y., Kang, S.Y.: Analysis of observational cases measured by MRR and PARSIVEl disdrometer for understanding the physical characteristics of precipitation (Korean). Atmosphere. 20, 37-47 (2010)

Cosma, S., Richard, E., Miniscloux, F.: The role of small-scale orographic features in the spatial distribution of precipitation. Q. J. Meteorol. Soc. 128, 75-92 (2002)

Field, P.R.: Aircraft observations of ice crystal evolution in an altostratus cloud. J. Atmos. Sci. 56, 1925 (1999)

K, Friedrich and S, Higgins, 2013: Articulating and stationary PARSIVEl disdrometer measurements in conditions with strong winds and rainfall. J. Atmo. and oceanic Tech., doi : https://doi.org/10.1175/ JTECH-D-12-002541

Harimaya, T. and N . Kanemura, 1995: Comparison of the riming growth of snow particles between coastal and inland area. J. meteor. Soc. Japan, 73, 25-36

Harimaya, T., Kawasato, Y.: Snowflake formation and its regional characteristics. J. Fac. Sci. Hokkaido Univ. 11, 793-809 (2001)

Harimaya, T., Sato, M.: Measurement of the riming amount on snowflakes. J. Fac. Sci. Hokkaido Univ. 4, 355-366 (1989)

Harimaya, T., Sato, M.: The riming proportion in snow particles falling on coastal area. J. meteor. Soc. Japan. 70, 57-65 (1992)

Heymsfield, A.J., Schmitt, C., Bansemer, A.: Ice cloud size distributions and pressure-dependent terminal velocities from in situ observations at temperatures from $0{ }^{\circ} \mathrm{C}$ to $-86^{\circ} \mathrm{C}$. J. Atmos. Sci. 70, 4123-4154 (2013)

Jeck Richard K., 1998: Snow and Ice Particle Size and Mass Concentrations at Altitudes up to $9 \mathrm{Km}(30,000 \mathrm{Ft})$, FAA report, $93 \mathrm{p}$

Löffler-Mang, M., Joss, J.: An optical disdrometer for measuring size and velocity of hydrometeor. J. Atmos. Ocean. Technol. 17, 130-139 (2000)

Mason, S.L., Chiu, J.C., Hogan, R.J., Tian, L.: Improved rain rate and drop size retrievals from airborne Doppler radar. Atmos. Chem. Phys. 17, 11 567-11 589 (2017)

Mott, R., Scipion, D., Schneebeli, M., Dawes, N., Berne, A., Lehning, M.: Orographic effects on snow deposition patterns in mountainous terrain. J. Geophys. Res.-Atmos. 119, 1419-1439 (2014)

Muller, C.L., Kidd, C., Fairchild, I.J., Baker, A.: Investigation in to cloud and precipitation over an urban area using micro rain radar, satellite remote sensing and fluorescence spectrophotometry. Atmos. Res. 96, 241-255 (2010)

Nam, K.-Y., Chang, K.-H., Kim, K.-E., Sung-Nam, O., Choi, Y.-J., Kim, K., Lee, D.-I., Kim, K.-L.: Method for analysis on optimization of averaging interval of rainfall rate measured by tipping-bucket rain gauge. Korean Journal of Remote Sensing. 24, 17-24 (2008)

OTT MESSTECHNIK GmbH \& Co, 2005: Operating instructions present weather sensor parsivel, www.ott-hydrometry.com, 28p

Rosenfeld an, D., Ulbrich, C.W.: Cloud microphysical properties, processes, and rainfall estimation opportunities. Meteorol. Monogr. 10, 217-227 (2003)

Sun-Hee, J., Im, E.-S., Han, S.-O.: The effect of topography and sea surface temperature on heavy snowfall in the Yeongdong region: a case study with high resolution WRF simulation, Asia-Pacific J. Atmos. Sci. 48, 259-273 (2012)

Timothy, K.I, Jin Teong Ong, and Choo, E.B.L, 2002: Raindrop size distribution using method of moments for terrestrial and satellite communication applications in Singapore. IEEE Trans. Antennas Propag., 50, 1420-1424

Uijlenhoet, R., Steiner, M., Smith, J.A.: Variability of raindrop size distribution in a SquallLine and implications for radar rainfall estimation. J. Hydrometeorol. 4, 43-61 (2003)

Ware, E.C., Schultz, D.M., Brooks, H.E., Roebber, P.J., Bruening, S.L.: Improving snowfall forecasting by accounting for the climatological variability of snow density. Weather Forecast. 21, 94-103 (2006)

Woods, C.P., Stoelinga, M.T., Locatelli, J.D.: Size spectra of snow particles measured in wintertime precipitation in the Pacific northwest. J. Atmos. Sci. 65, 189-205 (2008) 
You, C.-H., Lee, D.-I., Jang, M., Seo, K.-J., Kim, K.-E., Kim, B.-S.: The characteristics of rain drop size distributions using a POSS in Busan area. J. of the Korean Meteoro. Soc. 40, 713-724 (2004)

Yum, S.S., Cha, J.-W.: Suppression of very low intensity precipitation in Korea. Atmos. Res. 98, 118-124 (2010)
Yuter, S.E., Kingsmil, D.E., Nance, L.B., Löffler-Mang, M.: Observations of precipitation size and fall speed characteristics within coexisting rain and wet snow. J. Appl. Meteorol. Climatol. 45, 1450-1464 (2006)

Publisher's Note Springer Nature remains neutral with regard to jurisdictional claims in published maps and institutional affiliations. 